\title{
Clinical Features of Inflammatory Myopathies and Their Association with Malignancy: A Systematic Review in Asian Population
}

\author{
Patompong Ungprasert, ${ }^{1}$ Napat Leeaphorn,, Nattamol Hosiriluck, ${ }^{2}$ \\ Wikrom Chaiwatcharayut, ${ }^{3}$ Nischala Ammannagari, ${ }^{1}$ and Donald A. Raddatz ${ }^{1}$ \\ ${ }^{1}$ Department of Internal Medicine, Bassett Medical Center and Columbia University College of \\ Physicians and Surgeons, Cooperstown, NY 13326, USA \\ ${ }^{2}$ Department of Internal Medicine, Phramongkutklao College of Medicine, \\ Bangkok 10440, Thailand \\ ${ }^{3}$ Department of Internal Medicine, Faculty of Medicine, Chulalongkorn University, \\ Bangkok 10330, Thailand \\ Correspondence should be addressed to Patompong Ungprasert; patompong.ungprasert@bassett.org
}

Received 3 January 2013; Accepted 27 January 2013

Academic Editors: J. Bruges Armas, C. Chizzolini, and A. Wong

Copyright (C) 2013 Patompong Ungprasert et al. This is an open access article distributed under the Creative Commons Attribution License, which permits unrestricted use, distribution, and reproduction in any medium, provided the original work is properly cited.

\begin{abstract}
Introduction. Idiopathic inflammatory myopathies (IIMs) are a group of chronic systemic autoimmune diseases that mainly affect the skeletal muscle. The common subtypes include adult dermatomyositis (DM), polymyositis (PM), and inclusion body myositis (IBM). Most of the earlier studies that described the clinical characteristics of IIM as well as their association with cancer were conducted in Western population. Our study is the first systematic review that summarizes the clinical data of DM/PM in Asian population. Methods. We identified 14 case series of DM/PM that met our eligibility criteria. We then compared this data with that from previous reports from Europe and North America. Results. Our systematic review included 2518 patients. Dermatomyositis is more common, with the ratio of dermatomyositis to polymyositis being $1.36: 1$. $69 \%$ of them were females with mean age of 45.5 years. Extramuscular manifestations, including arthritis/arthralgia, dysphagia, and interstitial lung disease, are found in onethird of the patients. Malignancy was found in 10\% of patients, with lung and nasopharyngeal carcinomas being the most common malignancies associated with these myopathies. Conclusion. Clinical presentation of PM/DM appears to be similar in both Western and Asian populations. However, the type of associated malignancies in Asians differs from that in Caucasians. Ethnic background should be one of the factors that clinicians should consider while screening for malignancy.
\end{abstract}

\section{Introduction}

Idiopathic inflammatory myopathies (IIMs) are a group of chronic systemic autoimmune diseases that mainly affect the skeletal muscle. The common subtypes include adult dermatomyositis (DM), polymyositis (PM), and inclusion body myositis (IBM). In 1975, Bohan and Peter proposed the diagnostic criteria for DM and PM using clinical, laboratory, and pathological features which remain to be the gold standard for use in clinical studies $[1,2]$. Malignancies associated with these myopathies have been extensively reported in the medical literature since 1916 and then confirmed by subsequent metaanalyses [3-5].

Most of the earlier epidemiological studies that describe the clinical characteristics of IIM as well as their association with cancer come from Western population [4-6]. However, in recent years, several case series have been reported in the Asian population. This study aims to report a systematic review of case series reported exclusively in Asia in order to better characterize the demographics, the clinical data, and the associated malignancies in patients with $\mathrm{DM} / \mathrm{PM}$ in this population. 


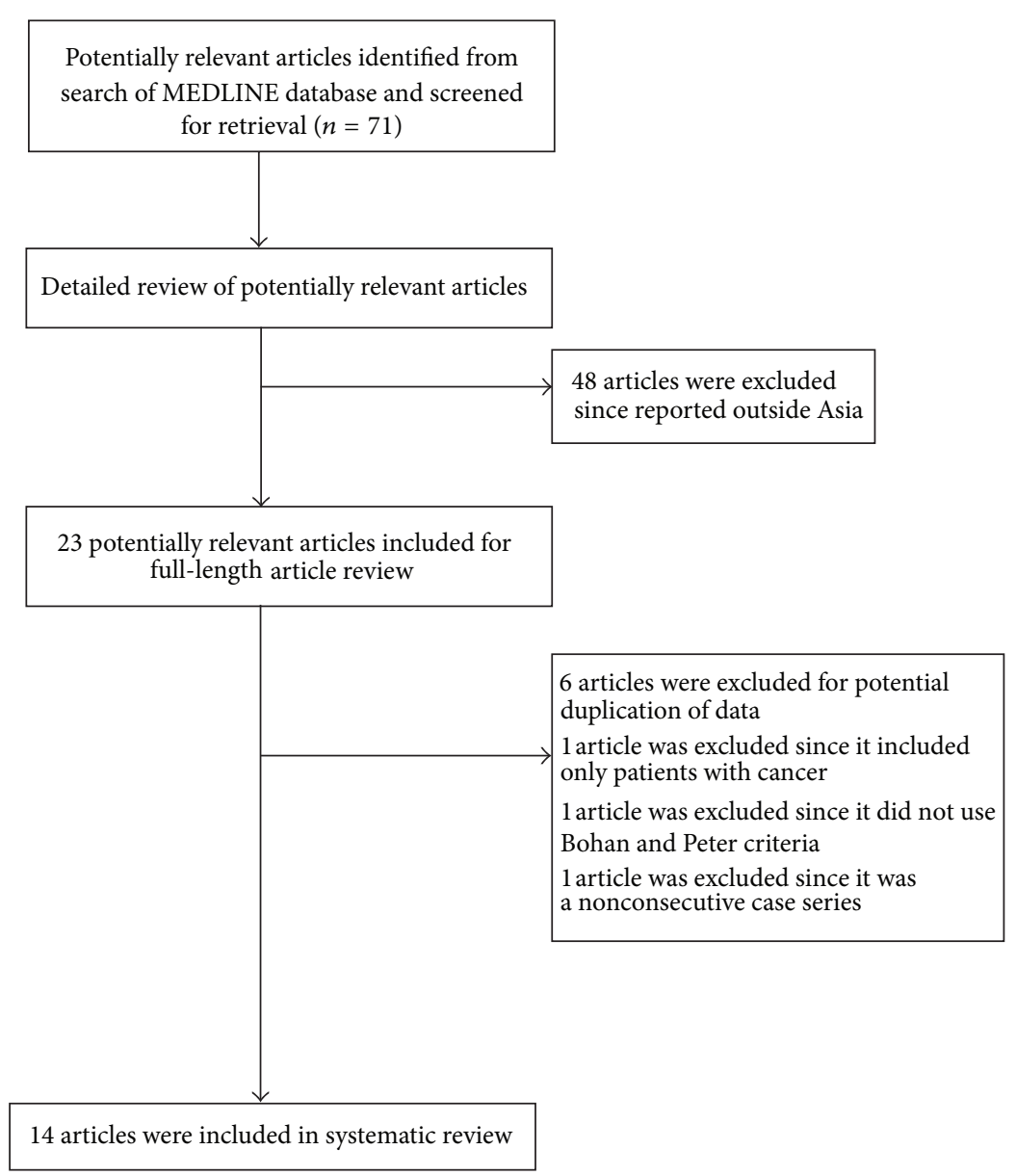

Figure 1: Case series identification.

TABle 1: Bohan and Peter diagnostic criteria for dermatomyositis/polymyositis.

(1) Symmetrical weakness of limb-girdle muscles and anterior neck flexor

(2) Muscle biopsy shows evidence of characteristic myositis

(3) Elevated serum skeletal muscle specific enzyme, especially creatinine phosphokinase

(4) Electromyographic (EMG) evidence of myositis

(5) Typical dermatomyositis rash, including heliotrope and Gottron's papules

Definite polymyositis: all of items (1)-(4); probable: any three of items (1)(4); possible: any two of items (1)-(4).

Definite dermatomyositis: item 5 plus any three of items (1)-(4); probable: item 5 plus any two of items (1)-(4); possible: item 5 plus any one of items (1)-(4).

\section{Material and Methodology}

We identified published case series that reported the patients with DM and PM that met the Bohan and Peter criteria for DM/PM (definite, probable, and possible) (Table 1) by searching the PubMed database (until November 2012) [1, 2]. We used the search terms "Polymyositis" OR "Dermatomyositis" and restricted our review to human study. We also manually searched the reference lists of all initially selected articles. We included only studies that were done in Asian countries in an attempt to summarize the clinical data of DM/PM exclusively in this population. When more than one case series was reported from the same institution or used the same database, we included only the case series with the largest number of patients and that with the most detailed clinical data to avoid duplication. We excluded case series that reported on fewer than five patients to minimize potential bias of reporting nonrepresentative cases.

\section{Data Assessment}

Our search strategy yielded 71 potentially relevant articles. After full length article review, 6 of them were excluded due to potential patient duplication [7-12], one study was excluded since it included only patients with cancer [13], one study was excluded since it did not use the Bohan and Peter criteria [14], and another study was excluded since it was a nonconsecutive case series [15].

14 case series met our inclusion criteria and were included for data analysis [16-29]. Figure 1 outlines our search methodology and selection process. 


\section{Results}

Tables 2 and 3 summarize the clinical and laboratory data along with the incidence of associated malignancy of the 14 case series that met our inclusion criteria. These case series comprised a total of 2518 patients. The largest studies contributed to more than a half of all the patients [25]. 7 studies were done in East Asia [21-25, 27, 28], 3 studies were done in South East Asia [17, 19, 29], 2 studies were conducted in South Asia [16, 20], and the other 2 studies were from the Middle East $[18,26]$.

4.1. Demographics and Clinical Features. Female predominance is seen in all series, ranging from $57 \%$ to $81 \%$. Patients tend to present in their fifth to sixth decade with the mean age being $45.5 \pm 5.1$ years. Dermatomyositis is more common in these series with the ratio of dermatomyositis to polymyositis of $1.36: 1$. Extramuscular manifestations include arthritis/arthralgia $(35.0 \pm 10.2 \%)$, dysphagia $(29.3 \pm 13.2 \%)$, and interstitial lung disease $(37.5 \pm 18.3 \%)$.

4.2. Laboratory Findings. Creatine kinase is elevated in the majority of patients with a mean of $3019.2 \pm 1088.4 \mathrm{IU} / \mathrm{L}$. Positive antinuclear antibody (ANA) is found in nearly half of the patients $(53.7 \pm 10.1 \%)$, while Anti-Jo-1 antibody is found in $10.7 \pm 3.8 \%$.

4.3. Association with Malignancy. Malignancy is found in 10.0 $\pm 6.4 \%$ of these patients. It is more prevalent in patients with DM than those with PM $(12.3 \pm 8.5 \%$ and $5.5 \pm 7.8 \%$, resp.). Nasopharyngeal carcinoma and lung cancer are the most common types of cancer $(1.88 \%)$, followed by breast, colon, gastric, and hepatobiliary tract cancers $(1.14 \%, 0.79 \%, 0.79 \%$, and $0.79 \%$, resp.).

\section{Discussion}

Most of the earlier epidemiological studies characterizing the clinical presentation of IIM come from Western countries, especially from Northern Europe, leaving the clinical manifestations of these diseases in Asian population unclear. However, in the recent years, several case series from Eastern population have been described in the literature. Here, we report the first systematic review of PM/DM in Asian population, emphasizing the clinical and laboratory features as well as their association with malignancy.

Consistent with the Caucasian studies, there is a striking female predominance, mostly in the fifth to the sixth decade of life (female to male ratio is $2.2: 1$ ). However, there are a couple of relatively small case series from India and the Middle East that reported an average age of mid-thirties. In contrast to the PM predominance in European and North American cohorts [30-34], DM is more prevalent in our study population, with the DM to PM ratio of 1.36:1 [25]. This might signify the role of ultraviolet radiation in their pathogenesis, as previously described in a study by Okada et al. [35].
Symmetric, progressive proximal muscle weakness is the hallmark of these myopathies. However, several nonmuscular manifestations have been commonly described. Our cohort is noted to have dysphagia in approximately one-third, which is consistent with the other epidemiological studies from Europe and North America [33, 36-38]. Interstitial lung disease (ILD), one of the major causes of morbidity and mortality in patients with IIM, is also found in about onethird of our patients, although the incidence varies widely from $11 \%$ to $74 \%$. This variability is, at least, partly related to the different methods used to identify ILD in each study and is also noted in studies from Western countries [39, 40].

ANA is consistently positive in approximately a half of the patients included in our systematic review. AntiJo-1 antibody, the most common type of myositis-specific autoantibody, is found in about $10 \%$ of our patients which is lower than $18-20 \%$ from 3 large studies from Europe and USA [41-43]. However, this finding is not unexpected, since ethnic variation in the frequency of myositis specific autoantibodies has been described. For example, anti-Jo-1 antibody is found in only $3 \%$ and $0 \%$ in Meso-American (Mexico and Guatemala) and French-Canadian populations, respectively $[44,45]$.

High incidence of malignancy is, again, noted in our study $(12.3 \pm 8.5 \%$ and $5.5 \pm 7.8 \%$ for DM and PM, resp.). Our incidence is comparable with data from Caucasian population [30-32, 34]. However, the frequency of a specific type of associated cancer in our population is different when compared to Caucasian studies. Nasopharyngeal carcinoma, which is rarely found in Caucasian cohort, is the most common type of cancer in this study (along with lung cancer), while gastric and hepatobiliary tract cancers, which are also uncommonly described in Caucasian studies, are the third most common ones. Interestingly, ovarian cancer, the predominant associated cancer in European and North American cohort, is relatively uncommon in our study, with the incidence of $0.43 \%$ (the 8 th most common associated cancer). These findings might confirm the role of IIM as a paraneoplastic process that can occur with any malignancy, and the particular type of malignancy associated may vary in different ethnic populations. Thus, ethnic background should be one of the factors that clinicians should consider while screening for malignancy. For example, based on our systematic review, attention should be particularly paid towards Ear-Nose-Throat exam while screening for cancer in $\mathrm{DM} / \mathrm{PM}$ patients of Asian descent.

\section{Conclusion}

In conclusion, this is a systematic review of PM/DM conducted in Asian population, as an attempt to better characterize the clinical characteristics and the incidence of associated malignancies in this population. Clinical presentation of PM/DM appears to be similar in both Western and Asian countries. Interestingly, even though with comparable overall incidence of malignancy, the incidence of a specific type of malignancy differs from the Caucasian population. These findings might ascertain the role of IIM as a paraneoplastic 


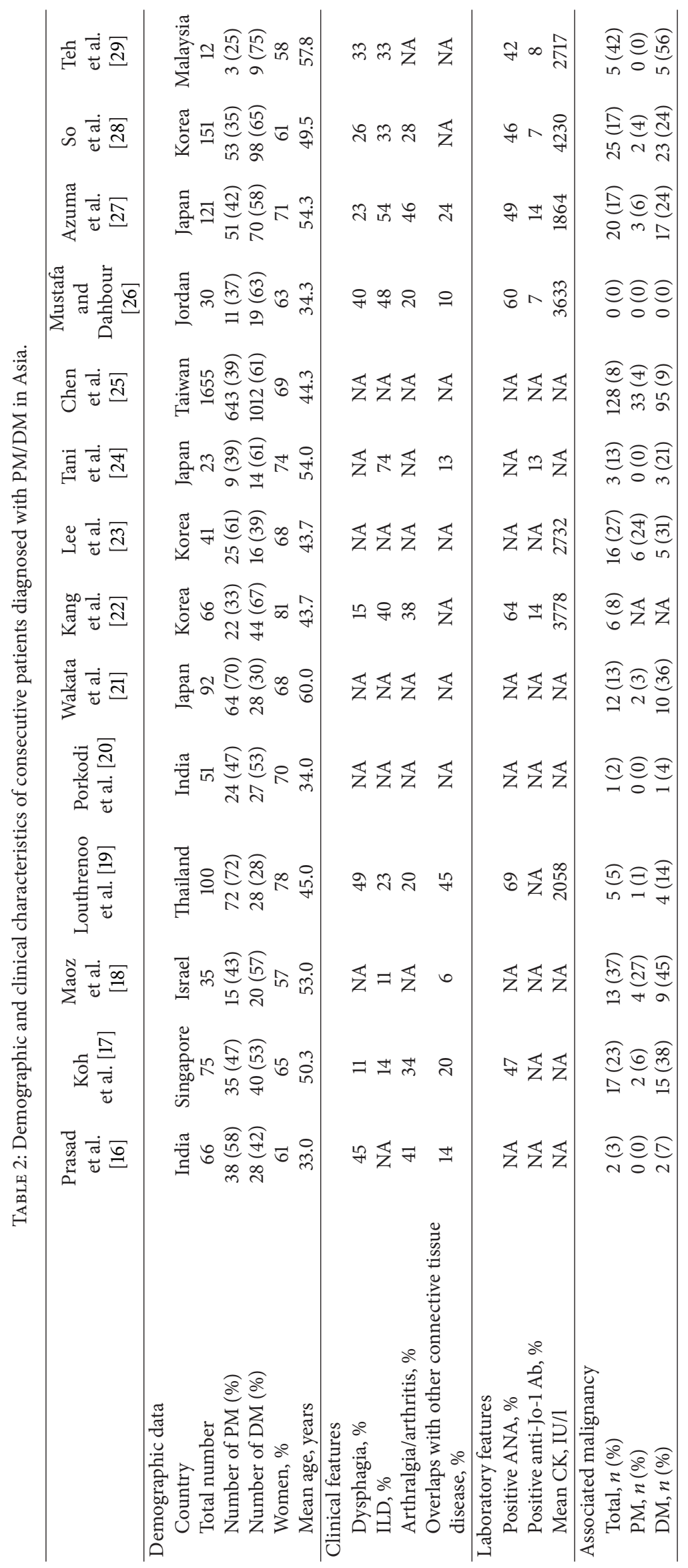




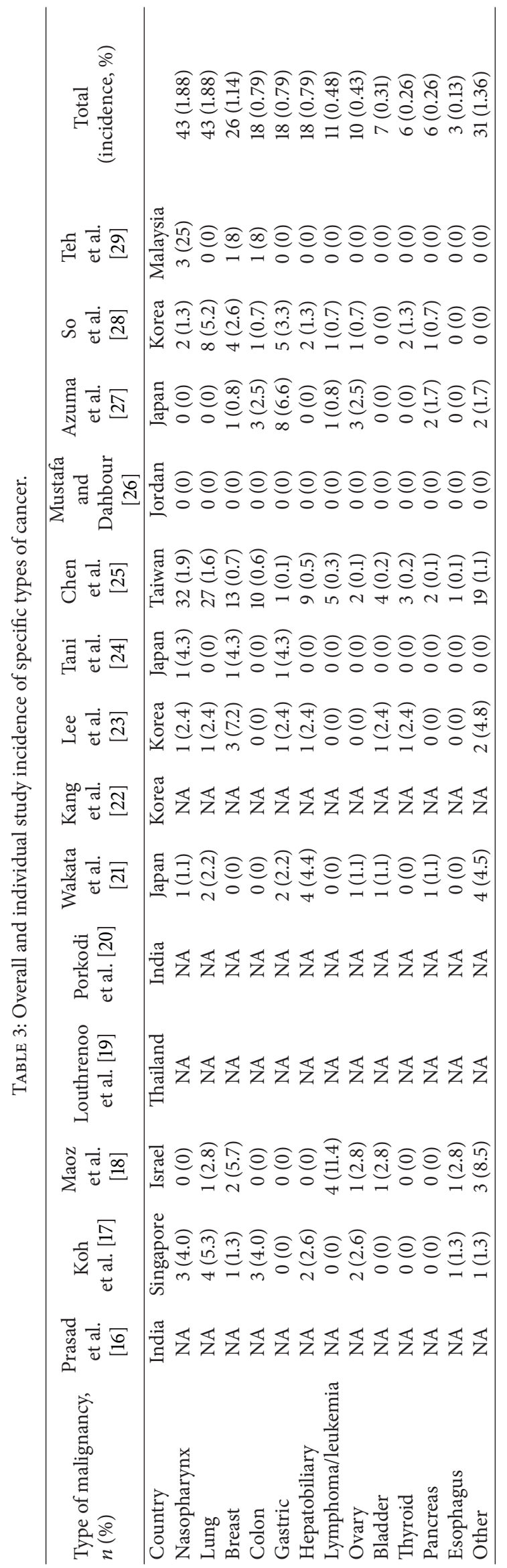


process, and ethnic background should be one of the factors that clinicians should consider while screening for malignancy.

\section{Conflict of Interests}

The authors do not have any financial or nonfinancial potential conflict of interests.

\section{Authors' Contribution}

All authors had access to the data and a role in writing the paper.

\section{References}

[1] A. Bohan and J. B. Peter, "Polymyositis and dermatomyositisI," The New England Journal of Medicine, vol. 292, no. 7, pp. 344347, 1975.

[2] A. Bohan and J. B. Peter, "Polymyositis and dermatomyositis (Second of two parts)," The New England Journal of Medicine, vol. 292, no. 8, pp. 403-407, 1975.

[3] G. Stertz, "Polymyositis," Berliner Klinische Wochenschrift, vol. 53, p. 489, 1916.

[4] D. Zantos, Y. Zhang, and D. Felson, "The overall and temporal association of cancer with polymyositis and dermatomyositis," Journal of Rheumatology, vol. 21, no. 10, pp. 1855-1859, 1994.

[5] R. Buchbinder and C. L. Hill, "Malignancy in patients with inflammatory myopathy," Current Rheumatology Reports, vol. 4, no. 5, pp. 415-426, 2002.

[6] V. Madan, H. Chinoy, C. E. M. Griffiths, and R. G. Cooper, "Defining cancer risk in dermatomyositis. Part I," Clinical and Experimental Dermatology, vol. 34, no. 4, pp. 451-455, 2009.

[7] T. H. Yen, P. C. Lai, C. C. Chen, S. Hsueh, and J. Y. Huang, "Renal involvement in patients with polymyositis and dermatomyositis," International Journal of Clinical Practice, vol. 59, no. 2, pp. 188-193, 2005.

[8] Y. Yamasaki, H. Yamada, T. Nozaki et al., "Unusually high frequency of autoantibodies to PL-7 associated with milder muscle disease in Japanese patients with polymyositis/dermatomyositis," Arthritis \& Rheumatism, vol. 54, no. 6, pp. 2004-2009, 2006.

[9] Y. L. Huang, Y. J. Chen, M. W. Lin et al., "Malignancies associated with dermatomyositis and polymyositis in Taiwan: a nationwide population-based study," British Journal of Dermatology, vol. 161, no. 4, pp. 854-860, 2009.

[10] C. F. Kuo, L. C. See, K. H. Yu et al., "Incidence, cancer risk and mortality of dermatomyositis and polymyositis in Taiwan: a nationwide population study," British Journal of Dermatology, vol. 165, no. 6, pp. 1273-1279, 2011.

[11] Y. Yamasaki, H. Yamada, M. Ohkubo et al., "Long term survival and associated risk factors in patients with adultonset idiopathic inflammatory myopathies and amyopathic dermatomyositis: experience in a single institute in Japan," The Journal of Rheumatology, vol. 38, no. 8, pp. 1636-1643, 2011.

[12] K. H. Yu, Y. J. Wu, C. F. Kuo et al., "Survival analysis of patients with dermatomyositis and polymyositis: analysis of 192 Chinese cases," Clinical Rheumatology, vol. 30, no. 12, pp. 1595-1601, 2011.

[13] C. N. Yeh, S. C. Chen, T. L. Hwang, M. F. Chen, C. C. Liaw, and H. L. Chan, "Breast carcinoma in patients with dermatomyositis: a retrospective analysis of eight cases," Chang Gung Medical Journal, vol. 25, no. 6, pp. 374-380, 2002.

[14] K. O. Wong, "Dermatomyositis: a clinical investigation of twenty-three cases in Hong Kong," British Journal of Dermatology, vol. 81, no. 7, pp. 544-547, 1969.

[15] T. Matsushita, M. Hasegawa, M. Fujimoto et al., "Clinical evaluation of anti-aminoacyl tRNA synthetase antibodies in Japanese patients with dermatomyositis," Journal of Rheumatology, vol. 34, no. 5, pp. 1012-1018, 2007.

[16] M. L. Prasad, C. Sarkar, S. Roy et al., "Idiopathic inflammatory myopathy: clinicopathological observations in the Indian population," British Journal of Rheumatology, vol. 31, no. 12, pp. 835839, 1992.

[17] E. T. Koh, A. Seow, B. Ong, P. Ratnagopal, H. Tjia, and H. H. Chng, "Adult onset polymyositis/dermatomyositis: clinical and laboratory features and treatment response in 75 patients," Annals of the Rheumatic Diseases, vol. 52, no. 12, pp. 857-861, 1993.

[18] C. R. Maoz, P. Langevitz, A. Livneh et al., "High incidence of malignancies in patients with dermatomyositis and polymyositis: an 11-year analysis," Seminars in Arthritis and Rheumatism, vol. 27, no. 5, pp. 319-324, 1998.

[19] W. Louthrenoo, N. Weerayutwattana, N. Lertprasertsuke, and W. Sukitawut, "Serum muscle enzymes, muscle pathology and clinical muscle weakness: correlation in Thai patients with polymyositis/dermatomyositis," Journal of the Medical Association of Thailand, vol. 85, no. 1, pp. 26-32, 2002.

[20] R. Porkodi, K. Shanmuganandan, M. Parthiban, R. Madhavan, and P. Rajendran, "Clinical spectrum of inflammatory myositis in South India- a ten year study," Journal of Association of Physicians of India, vol. 50, no. 10, pp. 1255-1258, 2002.

[21] N. Wakata, T. Kurihara, E. Saito, and M. Kinoshita, "Polymyositis and dermatomyositis associated with malignancy: a 30-year retrospective study," International Journal of Dermatology, vol. 41, no. 11, pp. 729-734, 2002.

[22] E. H. Kang, E. B. Lee, K. C. Shin et al., "Interstitial lung disease in patients with polymyositis, dermatomyositis and amyopathic dermatomyositis," Rheumatology, vol. 44, no. 10, pp. 1282-1286, 2005.

[23] S. W. Lee, S. Y. Jung, M. C. Park, Y. B. Park, and S. K. Lee, "Malignancies in Korean patients with inflammatory myopathy," Yonsei Medical Journal, vol. 47, no. 4, pp. 519-523, 2006.

[24] K. Tani, R. Tomioka, K. Sato et al., "Comparison of clinical course of polymyositis and dermatomyositis: a follow-up study in Tokushima University Hospital," Journal of Medical Investigation, vol. 54, no. 3-4, pp. 295-302, 2007.

[25] Y. J. Chen, C. Y. Wu, Y. L. Huang, C. B. Wang, J. L. Shen, and Y. T. Chang, "Cancer risks of dermatomyositis and polymyositis: a nationwide cohort study in Taiwan," Arthritis Research and Therapy, vol. 12, no. 2, article R70, 2010.

[26] K. N. Mustafa and S. S. Dahbour, "Clinical characteristics and outcomes of patients with idiopathic inflammatory myopathies from Jordan 1996-2009," Clinical Rheumatology, vol. 29, no. 12, pp. 1381-1385, 2010.

[27] K. Azuma, H. Yamada, M. Ohkubo et al., "Incidence and predictive factors for malignancies in 136 Japanese patients with dermatomyositis, polymyositis and clinically amyopathic dermatomyositis," Modern Rheumatology, vol. 21, no. 2, pp. 178183, 2011.

[28] M. W. So, B. S. Koo, Y. G. Kim, C. K. Lee, and B. Yoo, "Idiopathic inflammatory myopathy associated with malignancy: a retrospective cohort of 151 Korean patients with dermatomyositis 
and polymyositis," The Journal of Rheumatology, vol. 38, no. 11, pp. 2432-2435, 2011.

[29] C. L. Teh, J. S. Wong, and H. H. Soo, "Polymyositis and dermatomyositis in Sarawak: a profile of patients treated in the Sarawak general hospital," Rheumatology International, vol. 32, no. 1, pp. 265-268, 2012.

[30] D. Stockton, V. R. Doherty, and D. H. Brewster, "Risk of cancer in patients with dermatomyositis or polymyositis, and followup implications: a Scottish population-based cohort study," British Journal of Cancer, vol. 85, no. 1, pp. 41-45, 2001.

[31] B. Sigurgeirsson, B. Lindelof, O. Edhag, and E. Allander, "Risk of cancer in patients with dermatomyositis or polymyositis-a population-based study," The New England Journal of Medicine, vol. 326, no. 6, pp. 363-367, 1992.

[32] W. H. Chow, G. Gridley, L. Mellemkjar, J. K. Mclaughlin, J. H. Olsen, and J. F. Fraumeni, "Cancer risk following polymyositis and dermatomyositis: a nationwide cohort study in Denmark," Cancer Causes and Control, vol. 6, no. 1, pp. 9-13, 1995.

[33] G. S. Hoffman, W. A. Franck, D. A. Raddatz, and L. Stallones, "Presentation, treatment, and prognosis of idiopathic inflammatory muscle disease in a rural hospital," American Journal of Medicine, vol. 75, no. 3, pp. 433-438, 1983.

[34] C. L. Hill, Y. Zhang, B. Sigurgeirsson et al., "Frequency of specific cancer types in dermatomyositis and polymyositis: a population-based study," The Lancet, vol. 357, no. 9250, pp. 96100, 2001.

[35] S. Okada, E. Weatherhead, I. N. Targoff, R. Wesley, and F. W. Miller, "Global surface ultraviolet radiation intensity may modulate the clinical and immunologic expression of autoimmune muscle disease," Arthritis \& Rheumatism, vol. 48, no. 8, pp. 2285-2293, 2003.

[36] I. Marie, P. Y. Hatron, H. Levesque et al., "Influence of age on characteristics of polymyositis and dermatomyositis in adults," Medicine, vol. 78, no. 3, pp. 139-147, 1999.

[37] R. DeVere and W. G. Bradley, "Polymyositis: its presentation, morbidity and mortality," Brain, vol. 98, no. 4, pp. 637-666, 1975.

[38] I. Marie, E. Hachulla, P. Y. Hatron et al., "Polymyositis and dermatomyositis: short term and longterm outcome, and predictive factors of prognosis," Journal of Rheumatology, vol. 28, no. 10, pp. 2230-2237, 2001.

[39] T. Mimori, R. Nakashima, and Y. Hosona, "Interstitial lung disease in myositis: clinical subsets, biomarkers, and treatment," Current Rheumatology Reports, vol. 14, no. 3, pp. 264-274, 2012.

[40] M. Hirakata and S. Nagai, "Interstitial lung disease in polymyositis and dermatomyositis," Current Opinion in Rheumatology, vol. 12, no. 6, pp. 501-508, 2000.

[41] F. C. Arnett, I. N. Targoff, T. Mimori, R. Goldstein, N. B. Warner, and J. D. Reveille, "Interrelationship of major histocompatibility complex class II alleles and autoantibodies in four ethnic groups with various forms of myositis," Arthritis \& Rheumatism, vol. 39, no. 9, pp. 1507-1518, 1996.

[42] R. Brouwer, G. J. Hengstman, E. Vree et al., "Autoantibody profiles in the sera of European patients with myositis," Annals of the Rheumatic Diseases, vol. 60, no. 2, pp. 116-123, 2001.

[43] D. Vázquez-Abad and N. F. Rothfield, "Sensitivity and specificity of anti-Jo-1 antibodies in autoimmune diseases with myositis," Arthritis \& Rheumatism, vol. 39, no. 2, pp. 292-296, 1996.

[44] E. A. Shamim, L. G. Rider, T. P. O’Hanlon et al., "Clinical, serologic and genetic differences between U.S. Caucasians and Meso-Americans with idiopathic inflammatory myopathy (IIM)," Arthritis \& Rheumatism, vol. 42, p. S403, 1999.
[45] I. Uthman, D. Vazquez-Abad, and J. L. Senecal, "Distinctive features of idiopathic inflammatory myopathies in French Canadians," Seminars in Arthritis and Rheumatism, vol. 26, no. 1, pp. 447-458, 1996. 


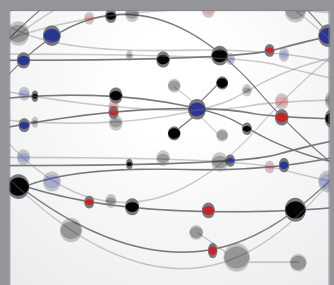

The Scientific World Journal
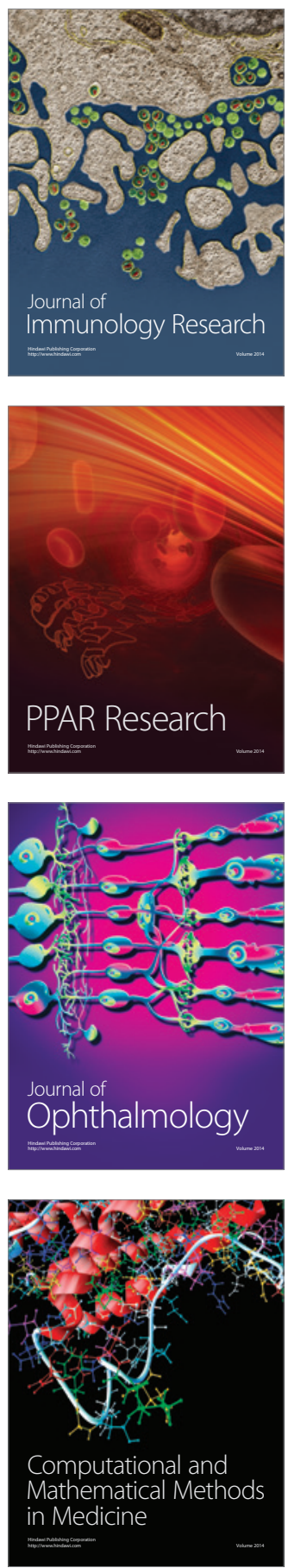

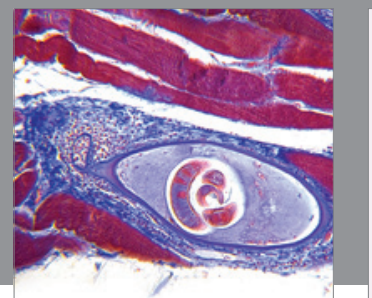

Gastroenterology

Research and Practice
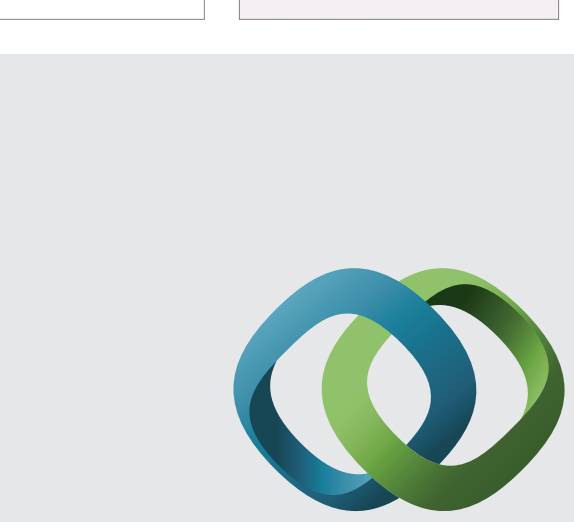

\section{Hindawi}

Submit your manuscripts at

http://www.hindawi.com
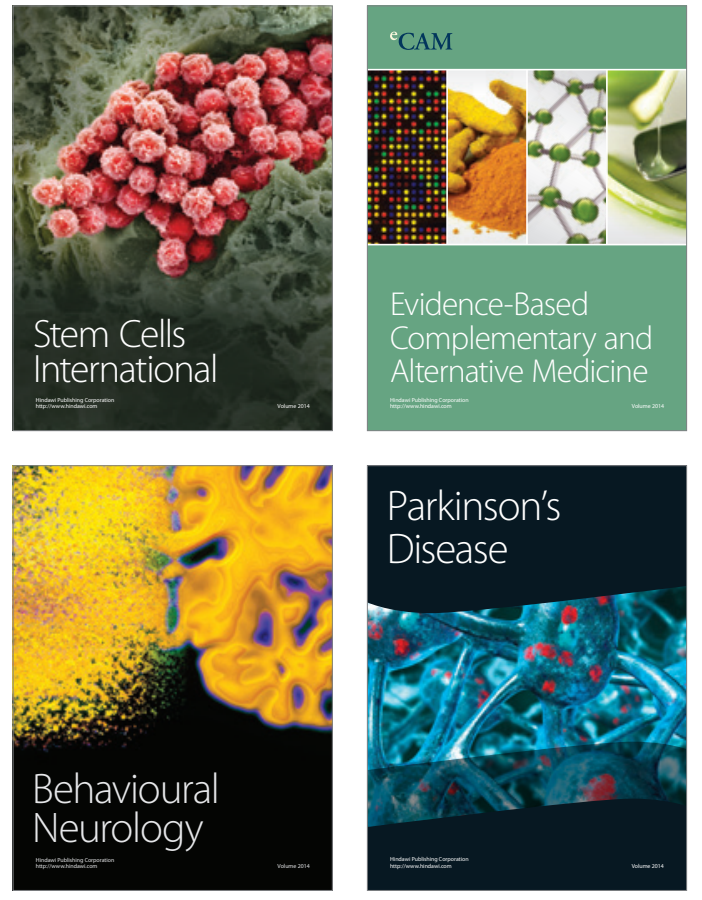
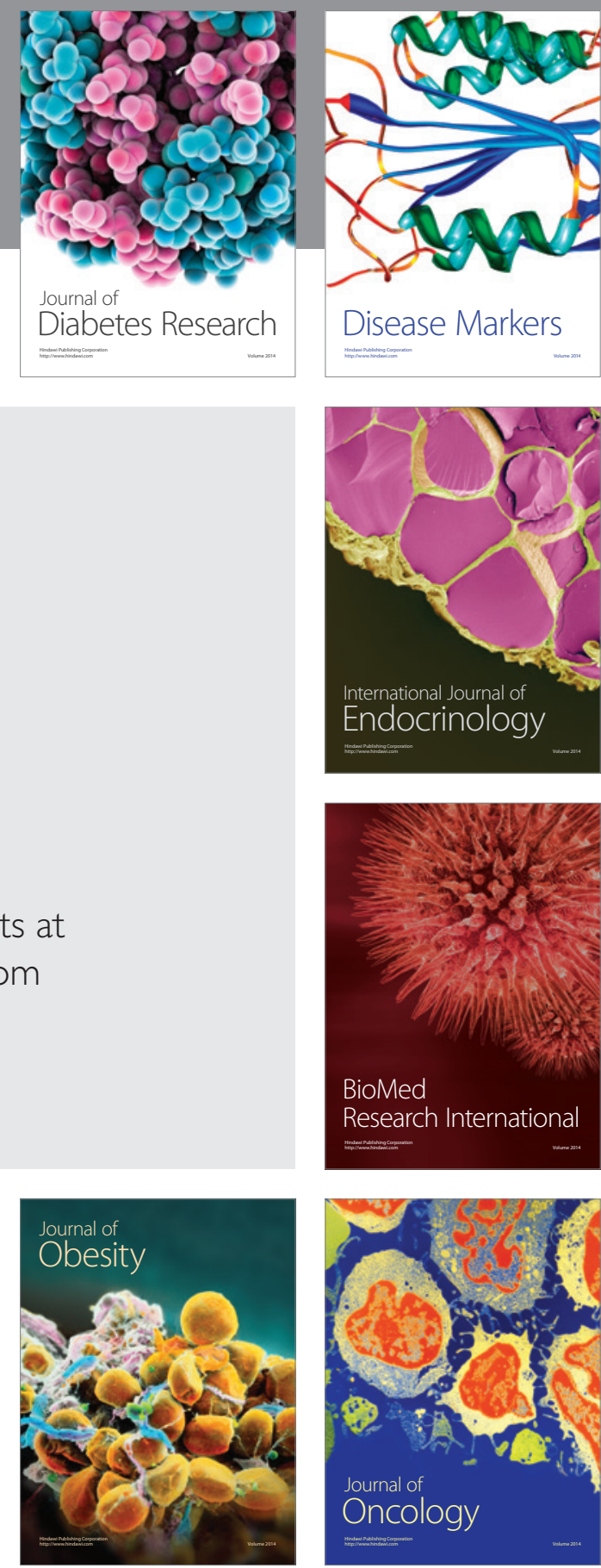

Disease Markers
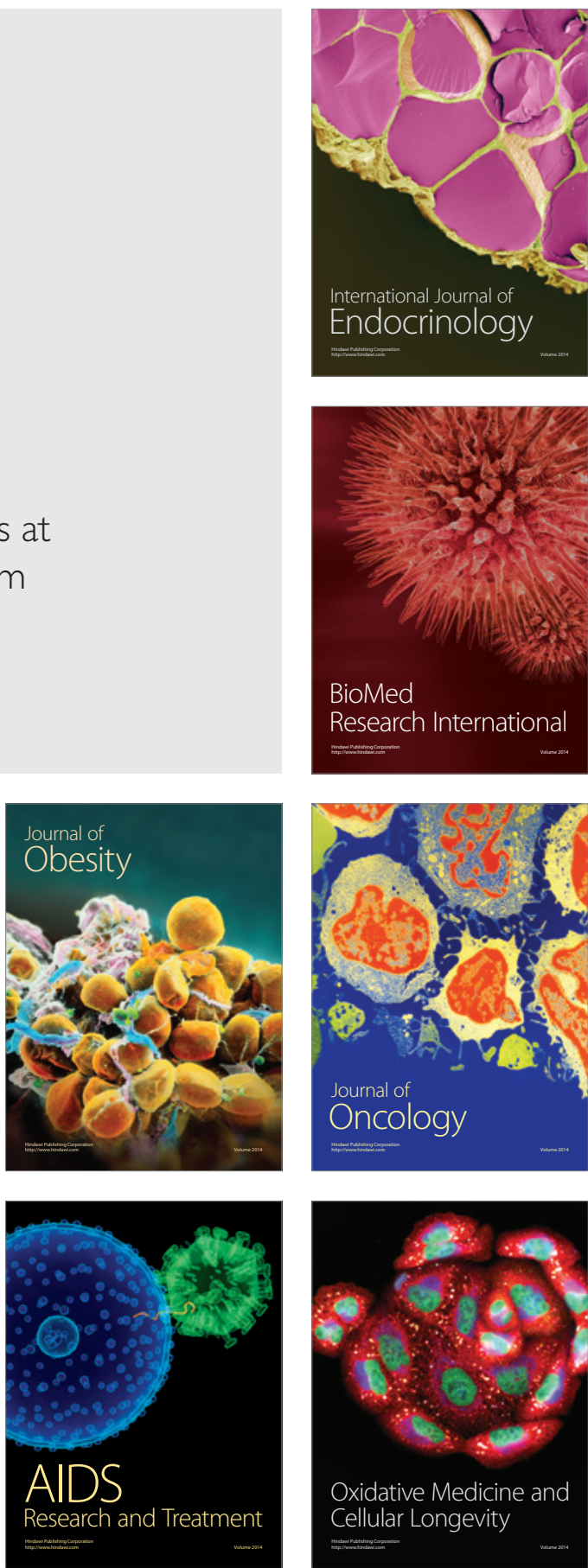